\title{
Hormones and diet: low insulin-like growth factor-I but normal bioavailable androgens in vegan men
}

\author{
NE Allen, PN Appleby, GK Davey and TJ Key \\ Cancer Epidemiology Unit, Imperial Cancer Research Fund, Gibson Building, Radcliffe Infirmary, Woodstock Road, Oxford OX2 6HE, UK
}

\begin{abstract}
Summary Mean serum insulin-like growth factor-I was 9\% lower in 233 vegan men than in 226 meat-eaters and 237 vegetarians $(P=0.002)$. Vegans had higher testosterone levels than vegetarians and meat-eaters, but this was offset by higher sex hormone binding globulin, and there were no differences between diet groups in free testosterone, androstanediol glucuronide or luteinizing hormone. (C) 2000 Cancer Research Campaign
\end{abstract}

Keywords: diet; insulin-like growth factor-I; sex hormones; vegan; meat-eaters

A western diet, believed to be a risk factor for prostate cancer (Giles and Ireland, 1997; Bosland et al, 1999) may increase risk by increasing androgen concentrations in the serum and prostate (Montie and Pienta, 1994). Data from prospective studies suggest that prostate cancer risk may be increased by high serum concentrations of bioavailable testosterone (Gann et al, 1996) and androstanediol glucuronide (A-diol-g), a serum marker of $5 \alpha-$ reductase activity and intraprostatic dihydrotestosterone (DHT) (Eaton et al, 1999). One prospective study has also found circulating levels of insulin-like growth factor-I (IGF-I), a polypeptide which interacts with androgens to stimulate cell proliferation, to be higher among men who subsequently developed prostate cancer than among controls (Chan et al, 1998).

The nutritional determinants of circulating hormone levels in men are poorly understood; some previous studies suggested that a vegetarian diet, low in saturated fat and high in dietary fibre, might reduce androgen levels, but the results have been inconsistent and based on small numbers (Deslypere and Vermeluen, 1984; Howie and Shultz, 1985; Bélanger et al, 1989; Key et al, 1990; Pusateri et al, 1990). We are not aware of any previous data on IGF-I concentrations in vegetarian and vegan men. We report here the results of a large cross-sectional study of serum concentrations of sex hormones and related proteins among 696 men of whom 226 were meat-eaters, 237 were vegetarians and 233 were vegans. We estimated that the study would have $80 \%$ power to detect $10 \%$ differences in hormone concentrations between diet groups at the $5 \%$ significance level.

\section{MATERIALS AND METHODS}

750 white male subjects were selected from the Oxford UK component of the European Prospective Investigation into Cancer and Nutrition (EPIC), and were for the current study if they had donated a blood sample prior to 1998. Subjects were excluded if they had a self-reported history of cancer $(n=16)$, or were taking

Received 30 November 1999

Revised 7 February 2000

Accepted 8 February 2000

Correspondence to: NE Allen medication known to influence hormone levels $(n=16)$. We also excluded those who had insufficient serum available for analysis ( $n=16)$ or had an estimated energy intake of $<3.1$ and $>18.40 \mathrm{~mJ} /$ day $(n=5)$. One further individual was excluded due to an SHBG level above the upper detection limit of $280 \mathrm{nmol} / \mathrm{l}$.

The present study includes 696 men of whom 226 were meateaters, 237 were vegetarians and 233 were vegans, recruited between 1994 and 1997. $30 \mathrm{ml}$ blood samples were collected for each subject and sent in the mail to the EPIC laboratory in Norfolk and aliquoted into plasma, serum, buffy coat and erythrocytes. Serum samples were stored in liquid nitrogen tanks at $-196^{\circ} \mathrm{C}$. Nutrient intakes were estimated from a validated semi-quantitative food frequency questionnaire by multiplying the nutrient content of a specific portion size of each food by the frequency of consumption (Bingham et al, 1997). Details of medical history and lifestyle characteristics were also recorded.

Assays for serum IGF-I, sex hormone binding globulin (SHBG), testosterone (T), A-diol-g, and luteinizing hormone (LH) were performed in the Clinical Biochemistry Laboratory at the John Radcliffe Hospital, Oxford in 1998. Plasma cholesterol assays were performed using automated enzymatic procedures at the Biochemistry Laboratory at Kings College, London in 1999. Each assay batch included equal numbers of meat-eaters, vegetarians and vegans, selected at random. All intra-assay coefficients of variation were less than $12 \%$. An estimate of the concentration of free testosterone (FT) was derived from the known concentrations of $\mathrm{T}$ and SHBG and assuming albumin concentration to be constant between individuals, using the formula based on the law of mass action (Södergaard et al, 1982).

Hormone concentrations and nutrient intakes were logarithmically or square-root transformed to approximate normal distributions. The mean hormone concentrations and their corresponding $95 \%$ confidence intervals (95\% CI) are presented as backtransformed values. Mean values adjusted for covariates were calculated by analysis of covariance.

\section{RESULTS}

Anthropometric and dietary characteristics are shown in Table 1. Vegetarians and vegans were significantly younger and had a 
Table 1 Anthropometric and nutritional characteristics by dietary group

\begin{tabular}{|c|c|c|c|c|}
\hline Variable & $\begin{array}{l}\text { Meat-eaters } \\
\quad(n=226)\end{array}$ & $\begin{array}{c}\text { Vegetarians } \\
\quad(n=237)\end{array}$ & $\begin{array}{l}\text { Vegans } \\
(n=233)\end{array}$ & $P$ value $^{a}$ \\
\hline Age (yrs) & $52.8(51.2-54.3)$ & $46.3(44.8-47.9)$ & $42.9(41.3-44.4)$ & $<0.0001$ \\
\hline Weight (kg) & $82.4(80.9-83.4)$ & $74.4(72.9-75.9)$ & $71.8(70.4-73.3)$ & $<0.0001$ \\
\hline Height (m) & $1.78(1.77-1.79)$ & $1.78(1.77-1.79)$ & $1.78(1.77-1.79)$ & 0.4739 \\
\hline $\mathrm{BMI}^{\mathrm{b}}$ & $26.1(25.7-26.5)$ & $23.4(22.0-23.8)$ & $22.7(22.3-23.1)$ & $<0.0001$ \\
\hline Energy (MJ) & $10.3(9.91-10.7)$ & $8.88(8.57-9.20)$ & $8.08(7.79-8.38)$ & $<0.0001$ \\
\hline Protein (\% energy) & $16.6(16.3-16.8)$ & $13.2(12.9-13.4)$ & $12.7(12.4-13.0)$ & $<0.0001$ \\
\hline Total fat (\% energy) & $34.0(33.2-34.8)$ & $31.0(30.3-31.8)$ & $29.9(29.1-30.7)$ & $<0.0001$ \\
\hline Saturated fatty acids (\% energy) & $11.8(11.5-12.1)$ & $8.71(8.38-9.03)$ & $4.87(4.55-5.20)$ & $<0.0001$ \\
\hline Monounsaturated fatty acids (\% energy) & $10.9(10.5-11.2)$ & $8.61(8.26-8.95)$ & 8.57 (8.22-8.92) & $<0.0001$ \\
\hline Polyunsaturated fatty acids (\% energy) & $5.39(5.06-5.72)$ & $6.12(5.79-6.44)$ & $8.17(7.85-8.50)$ & $<0.0001$ \\
\hline $\mathrm{P}: \mathrm{S}$ ratio ${ }^{c}$ & $0.49(0.44-0.54)$ & $0.78(0.73-0.83)$ & $1.71(1.66-1.76)$ & $<0.0001$ \\
\hline Cholesterol (mg/d) & 327 (301-355) & $112(108-127)$ & $20.8(19.2-25.5)$ & $<0.0001$ \\
\hline Alcohol (\% energy) & $5.83(5.07-6.58)$ & $4.30(3.57-5.03)$ & $3.96(3.22-4.70)$ & 0.0012 \\
\hline Non-starch polysaccharides (g/d) & $17.7(16.9-25.8)$ & $23.8(22.8-24.8)$ & $27.5(26.3-28.7)$ & $<0.0001$ \\
\hline
\end{tabular}

Age and anthropometric measurements are presented as arithmetic means and corresponding 95\% confidence interval (Cl); nutrients were natural logtransformed and are presented as geometric means and $95 \% \mathrm{Cl}$. aP value is test of heterogeneity, ${ }^{b} \mathrm{BMI}$ : body mass index $=\mathrm{weight}[\mathrm{kg}] / \mathrm{height}[\mathrm{m}]$, cpolyunsaturated:saturated fatty acid ratio.

Table 2 Mean hormone concentrations in three dietary groups

\begin{tabular}{|c|c|c|c|c|}
\hline Hormone & $\begin{array}{l}\text { Meat-eaters } \\
\quad(n=226)^{\mathrm{a}}\end{array}$ & $\begin{array}{l}\text { Vegetarians } \\
\qquad(n=237)^{\mathrm{a}}\end{array}$ & $\begin{array}{l}\text { Vegans } \\
(n=233)^{\mathrm{a}}\end{array}$ & $P$ value $^{\mathrm{b}}$ \\
\hline \multicolumn{5}{|l|}{ IGF-I (nmol/l) } \\
\hline Unadjusted for BMI & $20.1(19.3-20.8)$ & $20.1(19.4-20.8)$ & $18.5(17.8-19.2)$ & 0.002 \\
\hline Adjusted for BMI & $20.3(19.5-21.1)$ & $20.0(19.3-20.7)$ & $18.4(17.7-19.1)$ & 0.002 \\
\hline \multicolumn{5}{|l|}{ SHBG (nmol/l) } \\
\hline Unadjusted for BMI & $42.6(40.2-45.2)$ & $44.6(42.2-47.0)$ & $50.9(48.1-53.7)$ & 0.001 \\
\hline Adjusted for BMI & $45.7(43.1-48.4)$ & $43.6(41.4-46.0)$ & $48.7(46.0-51.4)$ & 0.017 \\
\hline \multicolumn{5}{|l|}{$\mathrm{T}$ (nmol/l) } \\
\hline Unadjusted for BMI & $19.3(18.3-20.3)$ & $20.5(19.6-21.4)$ & $22.3(21.3-23.4)$ & 0.003 \\
\hline Adjusted for BMI & 20.3 (19.3-21.3) & $20.1(19.2-21.0)$ & 21.7 (20.7-22.7) & 0.046 \\
\hline \multicolumn{5}{|l|}{ FT (nmol/l) } \\
\hline Unadjusted for BMI & $0.40(0.38-0.42)$ & $0.42(0.40-0.44)$ & $0.42(0.40-0.45)$ & 0.137 \\
\hline Adjusted for BMI & $0.42(0.40-0.44)$ & $0.43(0.41-0.45)$ & $0.44(0.42-0.46)$ & 0.471 \\
\hline \multicolumn{5}{|l|}{ A-diol-g (nmol/l) } \\
\hline Unadjusted for BMI & $8.93(8.40-9.47)$ & $8.45(7.97-8.93)$ & $8.63(8.14-9.14)$ & 0.443 \\
\hline Adjusted for BMI & $8.72(8.18-9.28)$ & $8.49(8.01-8.98)$ & 8.80 (8.29-9.32) & 0.646 \\
\hline \multicolumn{5}{|l|}{ LH (IU/I) } \\
\hline Unadjusted for BMI & $5.29(4.91-5.65)$ & $5.27(4.96-4.61)$ & $5.30(4.96-5.66)$ & 0.996 \\
\hline Adjusted for BMI & $5.43(5.06-5.82)$ & $5.23(4.92-5.57)$ & $5.20(4.87-5.56)$ & 0.632 \\
\hline \multicolumn{5}{|c|}{ Total cholesterol (nmol/l) } \\
\hline Unadjusted for BMI & $4.94(4.81-5.07)$ & $4.55(4.44-4.66)$ & $4.08(3.97-4.19)$ & $<0.0001$ \\
\hline Adjusted for BMI & $4.87(4.87-5.00)$ & $4.57(4.46-4.69)$ & $4.12(4.01-4.24)$ & $<0.0001$ \\
\hline
\end{tabular}

Back-transformed means presented with $95 \% \mathrm{Cl}$ in parentheses. Values are adjusted for age (in categories of 20-29, 30-39, 40-49, 50-59, 60-69, 70+), smoking status (never, past, $<10$ cigarettes/day, $10+$ cigarettes/day), vigorous exercise $(<2,2-45+$ hours/week), time of day of venipuncture $(<10,10-13.29$,

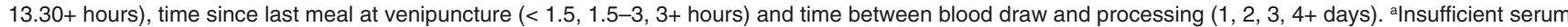
led to IGF-I measurement being unavailable in 1 subject, SHBG in 9 subjects, T in 20 subjects, FT in 25 subjects, A-diol-g in 5 subjects, LH in 20 subjects and total cholesterol in 8 subjects. ${ }^{\mathrm{b}} P$ value is test of heterogeneity.

lower weight and body mass index (BMI) than meat-eaters. Examination of nutrient intakes showed that vegetarians and vegans had lower intakes of energy, protein, total fat, saturated and monounsaturated fatty acids, and alcohol (each as percent energy) and lower intakes of dietary cholesterol compared to meat-eaters. Conversely, vegans had higher intakes of polyunsaturated fatty acids (\% energy), polyunsaturated:saturated fatty acid ratio and non-starch polysaccharides than meat.

All mean hormone concentrations are adjusted for age, smoking status, vigorous exercise, time of day of venipuncture, time since last eaten at venipuncture and time between venipuncture and blood processing. Mean hormone concentrations are presented with and without adjustment for BMI (Table 2). Vegan men had on average $9 \%$ lower IGF-I levels than meat-eaters $(P<0.01)$ and $8 \%$ lower levels than vegetarians $(P<0.01)$; adjustment for BMI made little difference to these values. Prior to adjustment for BMI, SHBG levels in vegans were $16 \%$ higher than in meat-eaters $(P<$ $0.0001)$, and $12 \%$ higher than in vegetarians $(P=0.0008)$; adjustment for BMI reduced these differences to $6 \%(P=0.02)$ and $10 \%$ $(P=0.004)$, respectively. Vegans had $13 \%$ higher T concentration than meat-eaters $(P=0.0001)$ and $8 \%$ higher than vegetarians $(P=$ $0.001)$; adjustment for BMI reduced these differences to $6 \%(P=$ $0.07)$ and $7 \%(P=0.02)$, respectively. Since an increase in SHBG generally causes an increase in total $\mathrm{T}$, we examined differences in mean $\mathrm{T}$ concentration after additionally adjusting for SHBG. This adjustment substantially reduced the difference in $\mathrm{T}$ between 
the three diet groups (adjusted means were 20.3, 20.5 and $21.2 \mathrm{nmol} / \mathrm{l}$ in meat-eaters, vegetarians and vegans respectively, test for heterogeneity; $P=0.312$ ). There were no significant differences in calculated FT, A-diol-g or LH between dietary groups. There were substantial differences in plasma total cholesterol, with vegans having $17 \%$ lower mean values than meat-eaters $(P<0.0001)$, and $10 \%$ lower values than vegetarians $(P<0.0001)$, and adjustment for BMI made little difference to these values.

\section{DIscussion}

This study is the largest to date to investigate differences in serum hormone concentrations between meat-eaters, vegetarians and vegans. The significant 9\% lower IGF-I concentration among vegan men compared to meat-eaters has not been reported before. IGF-I may play an important role in the aetiology of prostate cancer via its ability to interact with androgens to stimulate prostatic cell growth (Cohen et al, 1994), but its determinants are poorly understood. Chan et al (1998) found that men who subsequently developed prostate cancer had $8 \%$ higher serum IGF-I concentrations than men who remained healthy, suggesting that the $9 \%$ difference we observed is large enough to significantly alter prostate cancer risk.

SHBG was significantly higher in the vegans than in the meateaters, leading to a corresponding increase in $\mathrm{T}$ in order to maintain constant levels of FT, a pattern which has been found in previous smaller observational studies (Key et al, 1990; Pusateri et al, 1990). The differences in SHBG concentrations between dietary groups were reduced but not eliminated by adjusting for differences in BMI, suggesting that nutritional factors specific to a vegan diet may be important determinants of circulating SHBG levels, over and above their effect on BMI.

The significantly lower plasma total cholesterol concentration found among vegans compared to both vegetarians and meateaters, and the lower concentration in vegetarians compared to meat-eaters has been well-established in previous observational studies (Thorogood et al, 1987). These results confirm that large differences in lipid intake and lipoprotein physiology do exist between these dietary groups, but that these differences are not associated with circulating androgen concentrations.

The results did not support the hypothesis that meat-eaters have higher levels of bioavailable androgens than non meat-eaters. No differences in hormone levels were found between meat-eaters and lacto-ovo-vegetarians, suggesting that vegetarian diets may not alter prostate cancer risk, but the relatively low IGF-I levels in vegans might reduce their risk of prostate cancer. Prospective data have shown that vegetarians do not have significantly lower prostate cancer mortality rates than comparable non-vegetarians (Key et al, 1999), but these subjects were predominantly lactoovo-vegetarians and there are, as yet, no data on prostate cancer rates among vegans.

\section{ACKNOWLEDGEMENTS}

We thank all the participants of the EPIC study, the EPIC study staff at ICRF, Dr Dennis Quantrill and staff at the Clinical Biochemistry laboratory at the John Radcliffe Infirmary, Oxford, and TAB Sanders and Z Lloyd-Wright at the Nutrition and Dietetics Department at Kings College, London. This study was supported by the Imperial Cancer Research Fund and by the Europe Against Cancer Programme of the Commission of the European Communities.

\section{REFERENCES}

Bélanger A, Locong A, Noel C, Cusan L, Dupont A, Prévost J, Caron S and Sévigny J (1989) Influence of diet on plasma steroid and sex plasma binding globulin levels in adult men. J Steroid Biochem 32: 829-833

Bingham SA, Gill C, Welch A, Cassidy A, Runswick SA, Oakes S, Lubin R, Thurnham DI, Key TJ, Roe L, Khaw KT and Day NE (1997) Validation of dietary assessment methods in the UK arm of EPIC using weighed records, and 24-hour urinary nitrogen and potassium and serum vitamin $\mathrm{C}$ and carotenoids as biomarkers. Int J Epidemiol 26 (Suppl 1): S137-S151

Bosland MC, Oakley-Girvan L and Whittemore AS (1999) Dietary fat, calories and prostate cancer risk. J Natl Cancer Inst 91: 489-491

Chan JM, Stampfer MJ, Giovannucci E, Gann PH, Wilkinson P, Hennekens CH and Pollak M (1998) Plasma insulin-like growth factor-I and prostate cancer risk: a prospective study. Science 279: 563-566

Cohen P, Peehl DM and Rosenfeld RG (1994) IGF axis in the prostate. Horm Metab Res 26: 81-84

Deslypere JP and Vermeulen A (1984) Leydig cell function in normal men: effect of age, lifestyle, residence, diet and activity. J Clin Endocrinol Metab 59: 955-962

Eaton NE, Reeves GK, Appleby PN and Key TJ (1999) Endogenous sex hormones and prostate cancer: a quantitative review of prospective studies. Br J Cancer 80: $930-934$

Gann PH, Hennekens CH, Ma J, Longcope C and Stampfer MJ (1996) Prospective study of sex hormone levels and risk of prostate cancer. J Natl Cancer Inst $\mathbf{8 8}$ : $1118-1126$

Giles G and Ireland P (1997) Diet, nutrition and prostate cancer. Int J Cancer (Suppl 10): S13-S17

Howie BJ and Shultz TD (1985) Dietary and hormonal interrelationships among vegetarian Seventh Day Adventists and nonvegetarian men. Am J Clin Nutr 42: 127-134

Key TJ, Roe L, Thorogood M, Moore JW, Clark GM and Wang DY (1990) Testosterone, sex hormone binding globulin, calculated free testosterone and oestradiol in male vegans and omnivores. Br J Nutr 64: 111-119

Key TJ, Fraser GE, Thorogood M, Appleby PN, Beral V, Reeves G, Burr ML, Chang-Claude J, Frentzel-Beyme R, Kuzma JW, Mann J and McPherson K (1999). Mortality in vegetarians and non-vegetarians: detailed findings from a collaborative analysis of 5 prospective studies. Am J Clin Nutr 70 (Suppl): $516 \mathrm{~S}-524 \mathrm{~S}$

Montie JE and Pienta KJ (1994) A review of the role of androgenic hormones in the pathogenesis of benign prostatic hyperplasia and prostate cancer. Urology 43 : 892-899

Pusateri DJ, Roth WT, Ross JK and Shultz TD (1990) Dietary and hormonal evaluation of men at different risks for prostate cancer: plasma and fecal hormone-nutrient interrelationships. Am J Clin Nutr 51: 371-377

Södergaard RR, Backstrom T, Shanbhag V and Carstensen H (1982) Calculation of free and unbound fractions of testosterone and estradiol-17 $\beta$ to human plasma proteins at body temperature. J Steroid Biochem 6: 801-810

Thorogood M, Carter R, Benfield L, McPherson K and Mann JI (1987) Plasma lipids and lipoprotein cholesterol concentrations in people with different diets in Britain. BMJ 295: 351-353 